\title{
Association of the Hermansky-Pudlak syndrome type-3 protein with clathrin
}

\author{
Amanda Helip-Wooley ${ }^{1}$, Wendy Westbroek ${ }^{1}$, Heidi Dorward ${ }^{1}$, \\ Mieke Mommaas ${ }^{2}$, Raymond E Boissy ${ }^{3}$, William A Gahl ${ }^{1}$ and \\ Marjan Huizing*1
}

\begin{abstract}
Address: 1 Section on Human Biochemical Genetics, Medical Genetics Branch, National Human Genome Research Institute, NIH, Bethesda MD, USA, ${ }^{2}$ Department of Molecular Cell Biology, Leiden University Medical Center, Leiden, Netherlands and ${ }^{3}$ Department of Dermatology, University of Cincinnati College of Medicine, OH, USA

Email: Amanda Helip-Wooley - ahwooley@mail.nih.gov; Wendy Westbroek - wwestbro@mail.nih.gov;

Heidi Dorward - hdorward@mail.nih.gov; Mieke Mommaas - a.m.mommaas-kienhuis@lumc.nl; Raymond E Boissy - boissyre@email.uc.edu; William A Gahl - bgahl@helix.nih.gov; Marjan Huizing* - mhuizing@mail.nih.gov

* Corresponding author
\end{abstract}

Published: 13 September 2005

BMC Cell Biology 2005, 6:33 doi:10.1 |86/147|-2/21-6-33

This article is available from: http://www.biomedcentral.com/I47I-2/2I/6/33

(c) 2005 Helip-Wooley et al; licensee BioMed Central Ltd.

This is an Open Access article distributed under the terms of the Creative Commons Attribution License (http://creativecommons.org/licenses/by/2.0), which permits unrestricted use, distribution, and reproduction in any medium, provided the original work is properly cited.

\begin{abstract}
Background: Hermansky-Pudlak syndrome (HPS) is a disorder of lysosome-related organelle biogenesis characterized by oculocutaneous albinism and prolonged bleeding. These clinical findings reflect defects in the formation of melanosomes in melanocytes and dense bodies in platelets. HPS type-3 (HPS-3) results from mutations in the HPS3 gene, which encodes a 1004 amino acid protein of unknown function that contains a predicted clathrin-binding motif (LLDFE) at residues 172-176.

Results: Clathrin was co-immunoprecipitated by HPS3 antibodies from normal but not HPS3 null melanocytes. Normal melanocytes expressing a GFP-HPS3 fusion protein demonstrated partial colocalization of GFP-HPS3 with clathrin following a $20^{\circ} \mathrm{C}$ temperature block. GFP-HPS3 in which the predicted clathrin-binding domain of HPS3 was mutated (GFP-HPS3-delCBD) did not co-localize with clathrin under the same conditions. Immunoelectron microscopy of normal melanocytes expressing GFP-HPS3 showed co-localization of GFP-HPS3 with clathrin, predominantly on small vesicles in the perinuclear region. In contrast, GFP-HPS3-delCBD did not co-localize with clathrin and exhibited a largely cytoplasmic distribution.
\end{abstract}

Conclusion: HPS3 associates with clathrin, predominantly on small clathrin-containing vesicles in the perinuclear region. This association most likely occurs directly via a functional clathrin-binding domain in HPS3. These results suggest a role for HPS3 and its protein complex, BLOC-2, in vesicle formation and trafficking.

\section{Background}

Hermansky-Pudlak syndrome (HPS [MIM: 203300]) is an autosomal recessive disorder of vesicle biogenesis resulting in the dysfunction of lysosome-related organelles such as melanosomes and platelet dense bodies [1-4]. Affected patients have oculocutaneous albinism presenting as congenital nystagmus, reduced visual acuity, and varying degrees of hypopigmentation of the skin, hair, and irides 
[5-7]. In addition, a platelet storage pool deficiency, manifesting as absence of platelet dense bodies, causes loss of the secondary aggregation response $[2,8,9]$. Clinically, this results in easy bruising and epistaxis in childhood, prolonged bleeding during dental extractions and surgeries, and excessive menstrual and postpartum bleeding [9]. Some HPS patients also develop granulomatous colitis or a fatal pulmonary fibrosis $[9,10]$.

To date, seven genes have been identified as causes of human HPS subtypes (HPS-1 through HPS-7), and other genes identified in mouse models of HPS may also cause HPS in humans $[4,11]$. Of the human subtypes, only HPS2 ([MIM: 603401]) results from mutations in a gene (AP3B1) with a known function. AP3B1 codes for the $33 \mathrm{~A}$ subunit of adaptor complex-3 (AP-3), a coat protein that is involved in sorting transmembrane proteins to lysosomes and lysosome-related organelles [12-15]. This recognized function of AP-3 supports the paradigm that all types of HPS result from abnormal vesicle formation and/ or trafficking.

Each of the gene products of HPS1 ([MIM: 604982; [16,17]]), HPS3 ([MIM: 606118; [18,19]]), HPS4 ([MIM: 606682; [20,21]]), HPS5 ([MIM: 607521; [22,23]]), HPS6 ([MIM: 607522; [22]]), and HPS7 ([MIM: 607145; [24]]) is unique, although some HPS proteins interact with each other in Biogenesis of Lysosome-related Organelles Complexes or BLOCs $[22,24-26]$. The fact that these proteins have no homology to any known proteins, to each other, or to known functional domains makes them challenging candidates to investigate using in vitro methods.

In an attempt to understand the function of HPS gene products, we focused on HPS3, a unique protein with a predicted clathrin-binding domain. HPS-3 patients, with mutations in the HPS3 gene, have absent platelet dense bodies, mild to moderate hypopigmentation of skin and hair, iris transillumination, and patchy hypopigmentation of the fundus [19]. The mouse ortholog of human HPS-3, cocoa, demonstrates similar features $[27,28]$. The HPS3 gene was identified by homozygosity mapping using HPS patients from a central Puerto Rican genetic isolate [18]. HPS3 is located on chromosome 3q24 and has 17 exons and a 3,015-bp open reading frame that codes for a 1004-amino acid protein. The central Puerto Rican founder mutation in HPS3 is a 3.9-kb deletion encompassing exon 1 and its surrounding introns [18]. The central Puerto Rican HPS population is distinct from the HPS isolate in northwest Puerto Rico, in which a founder mutation in the HPS1 gene results in a severe form of HPS [16]. Several non-Puerto Rican HPS3 mutations, as well as an Ashkenazi Jewish founder mutation in HPS3, have now been identified [19].
The human HPS3 protein contains a predicted clathrinbinding motif (LLDFE) at residues $172-176$ that conforms to the consensus sequence $\mathrm{L}(\mathrm{L}, \mathrm{I})(\mathrm{D}, \mathrm{E}, \mathrm{N})(\mathrm{L}, \mathrm{F})(\mathrm{D}$, E). This consensus was determined by amino acid sequence alignment of the clathrin-binding regions in the beta subunits of adaptor proteins 1,2 , and $3(\beta 1, \beta 2, \beta 3 \mathrm{~A}$, and $\beta 3 \mathrm{~B}$ ), arrestin 3 , and amphiphysin I and II [29]. This 'clathrin box' is sufficient for binding to the amino terminal domain of the clathrin heavy chain [29]. The structures of peptide complexes containing the clathrinterminal domain and the clathrin-binding motifs of $\beta$ arrestin 2 and $\beta 3 A$ have been determined by crystallography [30]. Both of these peptides bind, via their clathrin box motifs, to the same site in the clathrin heavy chain's terminal domain, with nearly identical bound conformations.

Clathrin is the main component of protein coats that assist in the formation of vesicles budding from the transGolgi network (TGN), plasma membrane, and endosomes. Several clathrin-associated proteins regulate the assembly of clathrin triskelions, composed of three heavy chains and three light chains, into the polyhedral cages that provide structure to intracellular vesicles. Some of these proteins and protein complexes are also involved in sorting cargo into vesicles and directing their transport within the cell $[31,32]$.

HPS- 2 disease results from deficiency of the clathrin binding protein $\beta 3 \mathrm{~A}[12-15]$, supporting a possible role for other HPS proteins in clathrin binding. Hence, we investigated the clathrin binding function of the HPS3 protein in melanocytes and fibroblasts.

\section{Results}

Several avenues of investigation were pursued to substantiate the predicted clathrin-binding activity of HPS3. These studies employed the techniques of immunoprecipitation, immunofluorescence, live cell imaging, and immunoelectron microscopy.

\section{Immunoprecipitation}

Whole cell lysates prepared from normal melanocytes and from HPS3 null melanocytes, i.e., cells from a patient homozygous for the 3.9-kb HPS3 founder deletion [18], exhibited approximately equal amounts of clathrin (Figure $1 \mathrm{a}$, left panel). Each whole cell lysate was then immunoprecipitated with polyclonal HPS3 peptide antibodies. Clathrin, detected by antibodies to its heavy chain, coimmunoprecipitated with HPS3 in the normal lysates but not in the HPS3 null lysates (Figure 1a, right panel). These results were obtained using either of two different monoclonal anti-clathrin heavy chain antibodies. 
a

\begin{tabular}{|c|c|c|c|}
\hline \multicolumn{2}{|c|}{ lysate } & \multicolumn{2}{|c|}{ HPS3 IP } \\
\hline NL & HPS3 & $\mathrm{NL}$ & HPS3 \\
\hline vm & 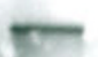 & & \\
\hline
\end{tabular}

b

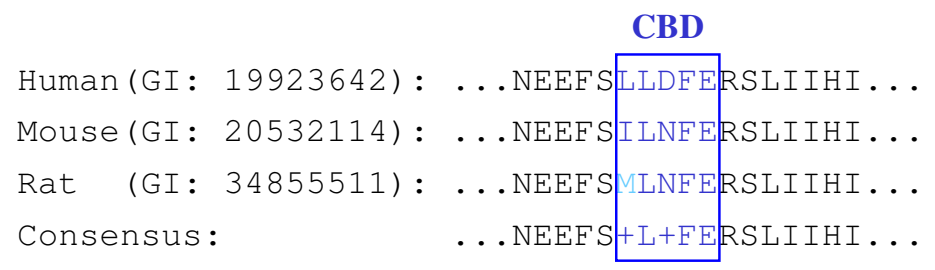

C

GFP-HPS3

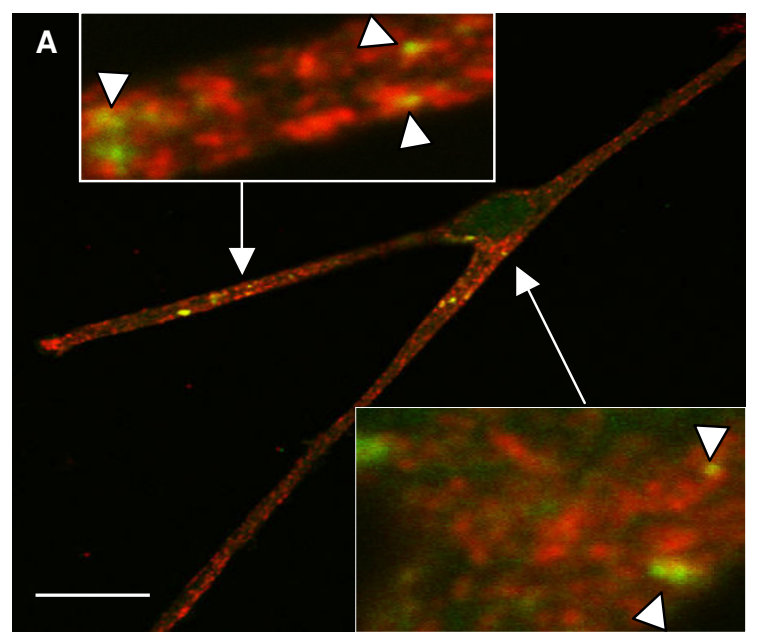

GFP-HPS3-delCBD

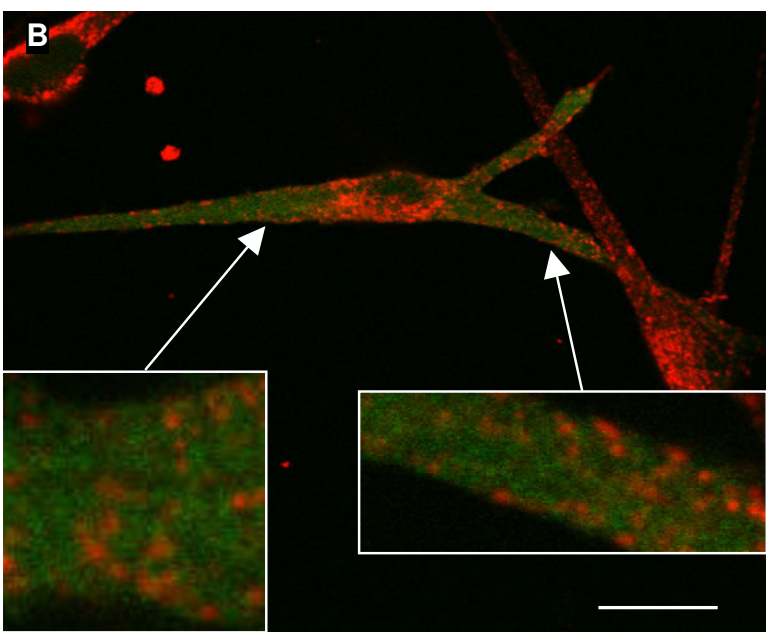

\section{Figure I}

Association of HPS3 with clathrin. (a) Immunoprecipitation of clathrin with HPS3 antibodies. Western blots of normal (NL) and HPS3-null (HPS3) melanocyte lysates treated with clathrin heavy chain antibodies. Equal amounts of clathrin were detected in both lysates [left panel]. The lysates were immunoprecipitated with HPS3 antibodies, electrophoresed, and immunoblotted using clathrin heavy chain antibodies. HPS3 antibodies immunoprecipitated clathrin only in the normal and not in the HPS3-null melanocyte lysates [right panel]. (b) Amino acid sequences of the predicted clathrin-binding domain (residues I72176 of human HPS3, shown in blue) in the human, mouse and rat HPS3 proteins, and the surrounding amino acid sequences. (c) Confocal immunofluorescence microscopy of representative normal melanocytes electroporated with GFP-HPS3 [A] and GFPHPS3-delCBD [B] (in green) and co-stained with antibodies to clathrin (in red). GFP-HPS3 partially co-localized with clathrin on small vesicles (arrowheads) [A], but GFP-HPS3-delCBD did not [B]. (Bar $=20 \mu \mathrm{m})$. 


\section{a}
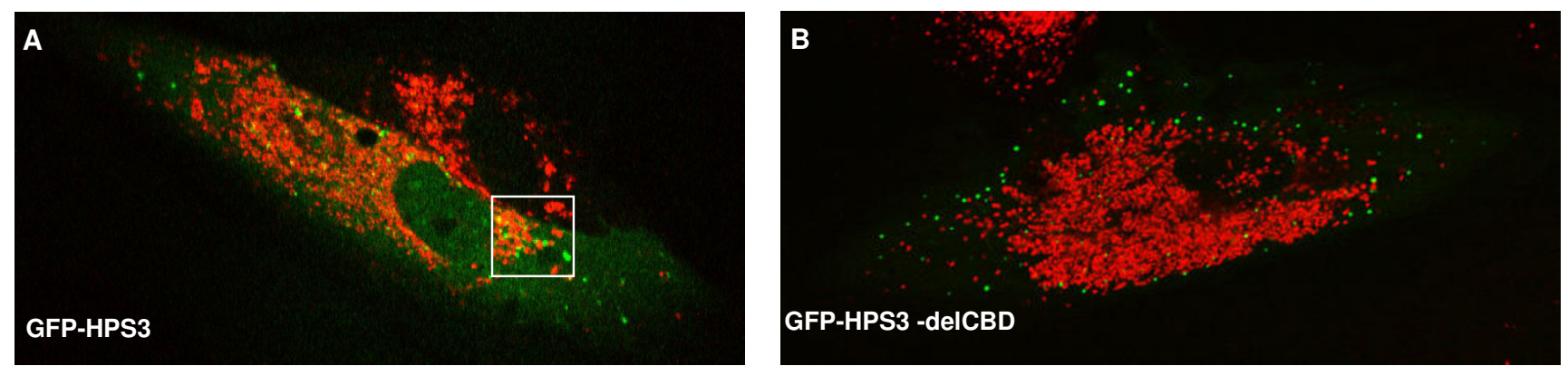

b
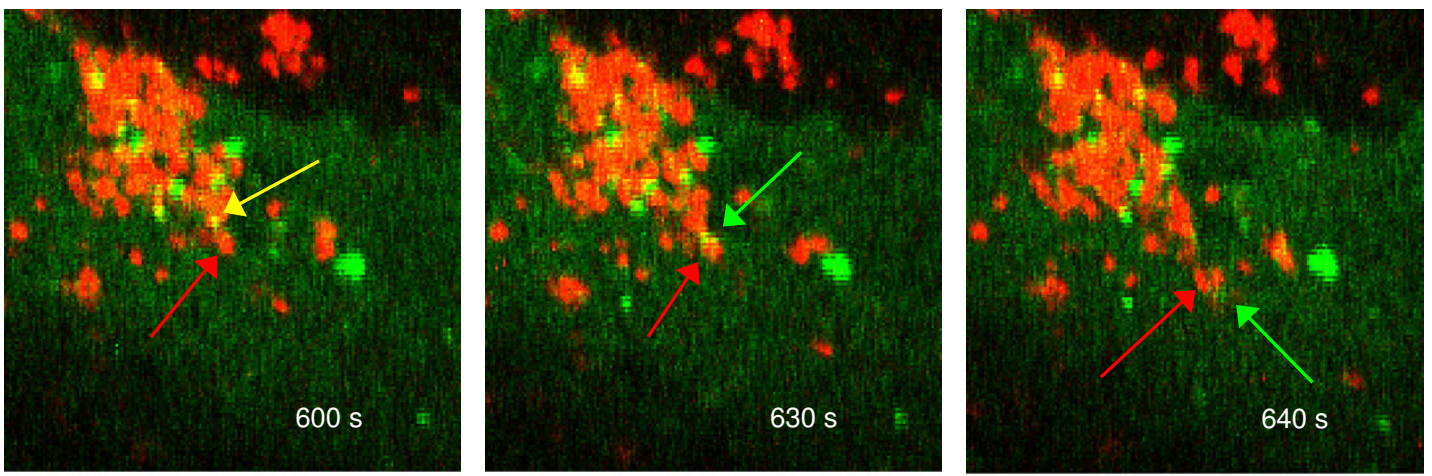

GFP-HPS3 and Lysotracker red

Figure 2

Live cell imaging of HPS3 and acidic vesicles. (a) Lysotracker Red stained acidic vesicle trafficking in live HPS3 null fibroblasts expressing GFP-HPS3 [A] or GFP-HPS3-delCBD [B]. Cells were imaged on a $37^{\circ} \mathrm{C}$ warming stage following a $2 \mathrm{~h}$ incubation at $20^{\circ} \mathrm{C}$. Lysotracker Red stained acidic vesicles and GFP-HPS3 transiently co-localized in the perinuclear area [A]. Inset shows the location of the time series shown in (b). GFP-HPS3-delCBD did not localize predominantly to the perinuclear area and showed no co-localization with Lysotracker Red [B]. (b) Time series showing co-trafficking of GFP-HPS3 and Lysotracker Red stained vesicles from the perinuclear area in HPS3 null fibroblasts. Note transient association of GFP-HPS3 with an acidic vesicle as it travels peripherally over a period of time (see [additional file I]).

\section{Immunofluorescence}

At residues 172-176, the HPS3 protein has a predicted clathrin-binding motif (LLDFE) that is conserved in mouse and rat (Figure 1b). Using site-directed mutagenesis, a GFP-HPS3-delCBD construct was created in which the clathrin-binding motif was converted to nonconserved amino acids (AAAPG). The interaction of clathrin-binding proteins with clathrin is a transient phenomena $[31,33,34]$. To maximize the likelihood of observing the association of GFP-HPS3 with clathrin by immunofluorescence, a $20^{\circ} \mathrm{C}$ temperature block was employed. Incubation at $20^{\circ} \mathrm{C}$ for $2 \mathrm{~h}$ was used to block trafficking out of the trans-Golgi $[35,36]$ and followed by transfer to $37^{\circ} \mathrm{C}$ for $5 \mathrm{~min}$ to release the temperature block and resume normal trafficking. Normal melanocytes expressing wildtype GFP-HPS3 or GFP-HPS3-delCBD, so treated, were then fixed and stained with clathrin heavy chain antibodies. Cells expressing GFP-HPS3 demonstrated partial colocalization with clathrin on one to several small vesicles in the perinuclear area (representative cell, Figure 1c[A]). In a representative experiment, 9 of 11 GFP-HPS3 expressing melanocytes showed this co-localization. In contrast, 0 of 10 cells exhibited co-localization of GFP-HPS3-del$\mathrm{CBD}$ with clathrin (Figure $1 \mathrm{c}[\mathrm{B}] ; \mathrm{p}<0.001$ by Chi-square analysis). 
Table I: Quantitation of immunogold label in normal melanocytes transfected with GFP-HPS3 or GFP-HPS3-deICBD'

\begin{tabular}{lcccc}
\hline & Gold Particles & Clathrin Association \\
\hline Intracellular compartment & GFP-HPS3 & GFP-HPS3-delCBD & GFP-HPS3 & GFP-HPS3-delCBD \\
\hline Small vesicles in Golgi area ${ }^{2,3}$ & 57 & 8 & 53 & 1 \\
Golgi stacks & 1 & 1 & 0 & 0 \\
Other small vesicles & 15 & 16 & 9 & 3 \\
Endosomal structures $^{3}$ & 23 & 17 & 15 & 1 \\
Mitochondria $_{\text {Melanosomes }}$ & 2 & 2 & 0 & 0 \\
Nucleus & 3 & 1 & 0 & 0 \\
Cytoplasm $^{2}$ & 2 & 63 & 0 & 3 \\
Total $^{3}$ & 8 & 110 & 0 & 77 \\
\hline
\end{tabular}

I Anti-GFP immunogold particles were counted in a total of 28 GFP-HPS3 and 25 GFP-HPS3-delCBD expressing cells

2 Difference in number of gold particles per compartment, for GFP-HPS3-delCBD compared with GFP-HPS3, is statistically significant by Chi square analysis $(p<0.001)$

3 Difference in number of gold particles found in association with clathrin, for GFP-HPS3-delCBD compared with GFP-HPS3, is statistically significant by $C h i$ square analysis $(p<0.00 I)$

\section{Live cell imaging}

Trafficking of acidic vesicles, stained with Lysotracker Red, was followed in live HPS3 null fibroblasts expressing either GFP-HPS3 (Figure 2a[A]) or GFP-HPS3-delCBD (Figure $2 \mathrm{a}[\mathrm{B}]$ ). Following a $20^{\circ} \mathrm{C}$ temperature block and transfer to $37^{\circ} \mathrm{C}$, acidic vesicles and GFP-HPS3 clustered together in the perinuclear area (Figure $2 \mathrm{~b}[\mathrm{~A}]$ ). GFP-HPS3 transiently interacted with acidic vesicles and, in some cases (arrows, Figure 2b), emerged together with them from the perinuclear area (Figure $2 \mathrm{~b}$ and [Additional file 1]). In contrast, following a $20^{\circ} \mathrm{C}$ block and transfer to $37^{\circ} \mathrm{C}$, GFP-HPS3-delCBD was predominantly localized in a punctate pattern in the periphery of the cell; no association of GFP-HPS3-delCBD with acidic vesicles was observed (Figure 2a[B] ).

\section{Immunoelectron microscopy}

Normal melanocytes were fixed approximately $9 \mathrm{~h}$ after transfection with GFP-HPS3. Expression of the GFP-HPS3 fusion protein was low at this time, thus minimizing aggregation and other artifacts that can occasionally be observed in overexpressing cells. Normal melanocytes transfected with GFP-HPS3-delCBD were fixed later (approximately $24 \mathrm{~h}$ after transfection) because of the very low levels of expression obtained with this construct. No aggregates were observed in the GFP-HPS3-delCBD transfected cells.

GFP-HPS3 localized predominantly to small (50-100 $\mathrm{nm}$ ) vesicles in the Golgi region (57 of 111 (51\%) antiGFP immunogold particles; Table 1) and the vast majority of these particles ( 53 of 57 (93\%)) co-localized with clathrin (Figure 3, arrowheads; Table 1). At high magnification,
GFP-HPS3 labeling was demonstrated on well-defined clathrin-containing vesicles (Figure $3[\mathrm{~B}, \mathrm{D}, \mathrm{E}]$ ). Some of these small clathrin-containing vesicles were found near larger endosomal structures (Figure 3[B,D]). GFP-HPS3 labeling was generally less abundant on large endosomal structures than on small vesicles (23 of $111(21 \%)$ of antiGFP immunogold particles found on endosomes) and fewer of these particles co-localized with clathrin (15 of $23(65 \%)$; Figure 3[B,D], Table 1).

In contrast, GFP-HPS3-delCBD expressing cells demonstrated very few anti-GFP immunogold particles on small vesicles in the Golgi region ( 8 of $110(7 \%)$ ) and these were only rarely found in association with clathrin ( 1 of 8 $(13 \%)$; Figure 4 , Table 1$)$. The majority of anti-GFP immunogold particles localized to the cytoplasm of GFPHPS3-delCBD expressing cells (63 of $110(57 \%)$ ), compared with only 7\% (8 of 111) in GFP-HPS3 expressing cells (Figures 3 and 4, Table 1). These differences were statistically significant by Chi square analysis $(\mathrm{p}<0.001$; Table 1).

No appreciable GFP-HPS3 or GFP-HPS3-delCBD labeling was observed on clearly identifiable Golgi stacks (Figure $3[\mathrm{~A}, \mathrm{C}]$, Figure $4[\mathrm{D}]$, Table 1 ). As expected, clathrin labeling appeared much more abundant than GFP labeling in GFP-HPS3 or GFP-HPS3-delCBD expressing melanocytes. Similar amounts of GFP labeling per cell were detected in GFP-HPS3 and GFP-HPS3-delCBD expressing cells and no GFP labeling was observed in untransfected cells. Not all clathrin-containing membranes were associated with GFP-HPS3, but the majority of GFP-HPS3 appeared to be associated with a clathrin-containing membrane. 

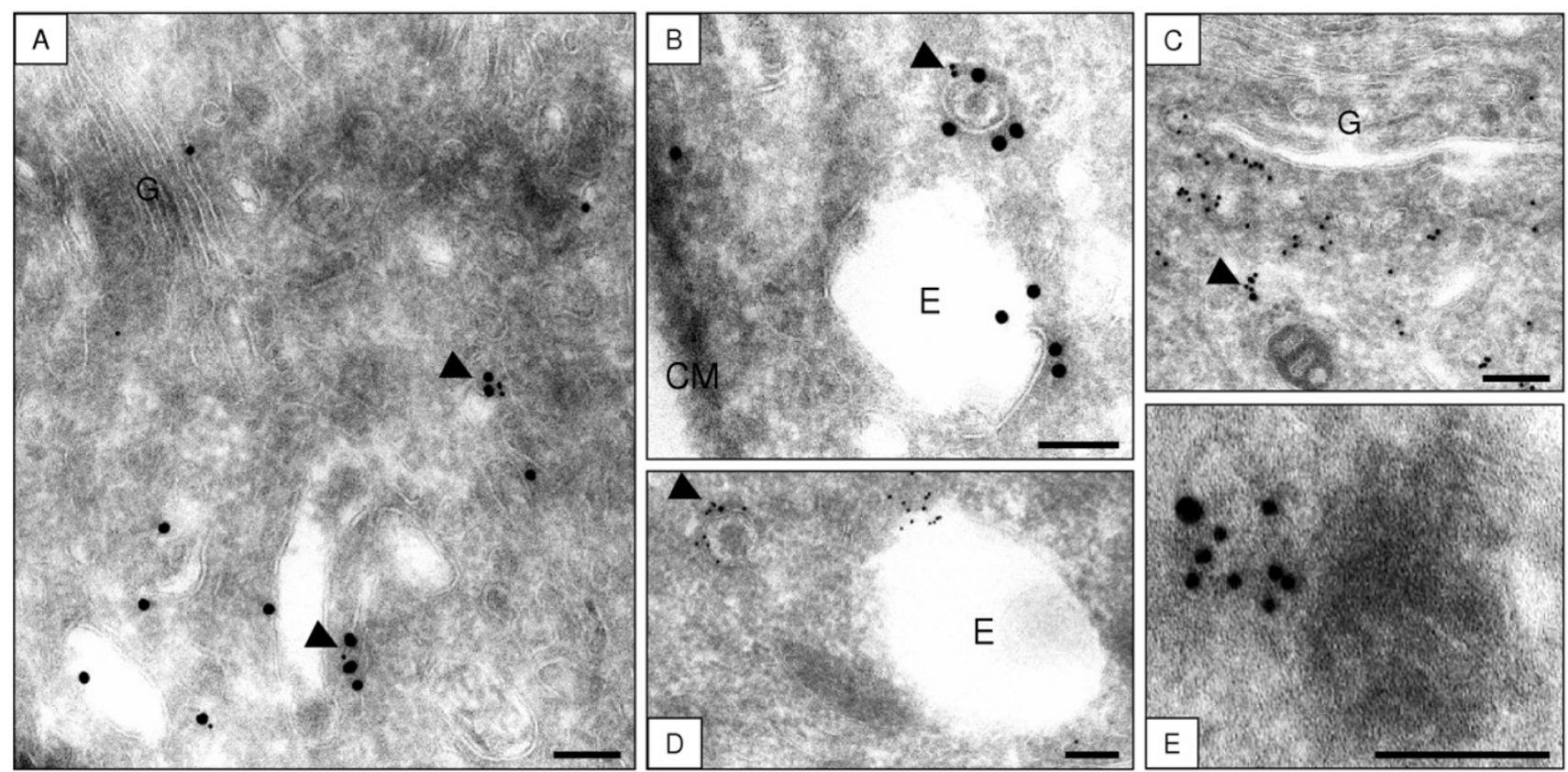

\section{Figure 3}

Immunoelectron micrographs demonstrating co-localization of GFP-HPS3 and clathrin. Double-labeling of antiGFP (I0-nm gold) and anti-clathrin (20-nm gold) [A, B], or the reverse labeled anti-clathrin (10-nm gold) and anti-GFP (I5-nm gold) $[C, D, E]$ in normal melanocytes electroporated with GFP-HPS3. Co-localization of the two labels was shown on small $(50-100 \mathrm{~nm})$ clathrin-containing vesicles (arrowheads) in the Golgi region [A and C]. Co-localization was observed on small clathrin-labeled vesicles (arrowheads) but not on neighboring large endosomal structures $[B$ and $D]$. High magnification of a small clathrin containing vesicle labeled with GFP-HPS3 [E]. CM = Cell Membrane, G = Golgi area, E = Endosomal structure. Bar $=100 \mathrm{~nm}$

\section{Discussion}

HPS 3 is unusual among HPS proteins in that it contains a predicted functional domain, i.e., a clathrin-binding motif (LLDFE) (Figure 1b). In this report, we describe evidence for the association of HPS3 with clathrin. We demonstrated that clathrin co-immunoprecipitates with endogenous HPS 3 in normal melanocytes; no clathrin was immunoprecipitated in the absence of HPS3, i.e., in HPS3 null cells. The necessity of the clathrin-binding domain in HPS3 is supported by the partial co-localization of GFP-HPS 3 with clathrin only when this domain is present, as demonstrated by both fluorescence and immunoelectron microscopy studies. Furthermore, localization and trafficking of GFP-HPS3 with acidic vesicles (labeled with Lysotracker Red) depends upon an intact clathrinbinding domain.

The presence of a conserved clathrin-binding motif in HPS3, combined with the supportive data mentioned above, indicates that HPS3 most likely binds clathrin directly. We cannot, however, rule out the possibility that HPS3 interacts indirectly with clathrin. Recent studies in mouse [37] and human [38] have shown that HPS3 (cocoa mouse) interacts with HPS5 (ruby-eye-2 mouse) and HPS6 (ruby-eye mouse) in the BLOC-2 complex. Hence, HPS3 may function as an essential component of a complex, such as BLOC-2, in which another member binds clathrin. This seems unlikely, however, since HPS5 and HPS6 have no conserved clathrin-binding sequence motifs.

In our ultrastructural studies, GFP-HPS3 was found primarily on small ( 50 to $100 \mathrm{~nm}$ ) clathrin containing vesicles in the perinuclear/Golgi region of normal melanocytes. Mutation of the clathrin-binding domain of HPS3 resulted in a largely cytoplasmic distribution of the fusion protein, suggesting that the clathrin-binding domain is necessary for the correct localization of HPS3 and that clathrin recruits HPS3 to small vesicles. Interestingly, no GFP-HPS3 was seen on Golgi stacks or on vesicles budding from the TGN, nor was it localized to large endosomal structures or mature melanosomes. In melanocytes from HPS3 deficient patients, DOPA histochemistry (used to identify extra-melanosomal sites of functional tyrosinase) detected $50 \mathrm{~nm}$ DOPA positive ves- 

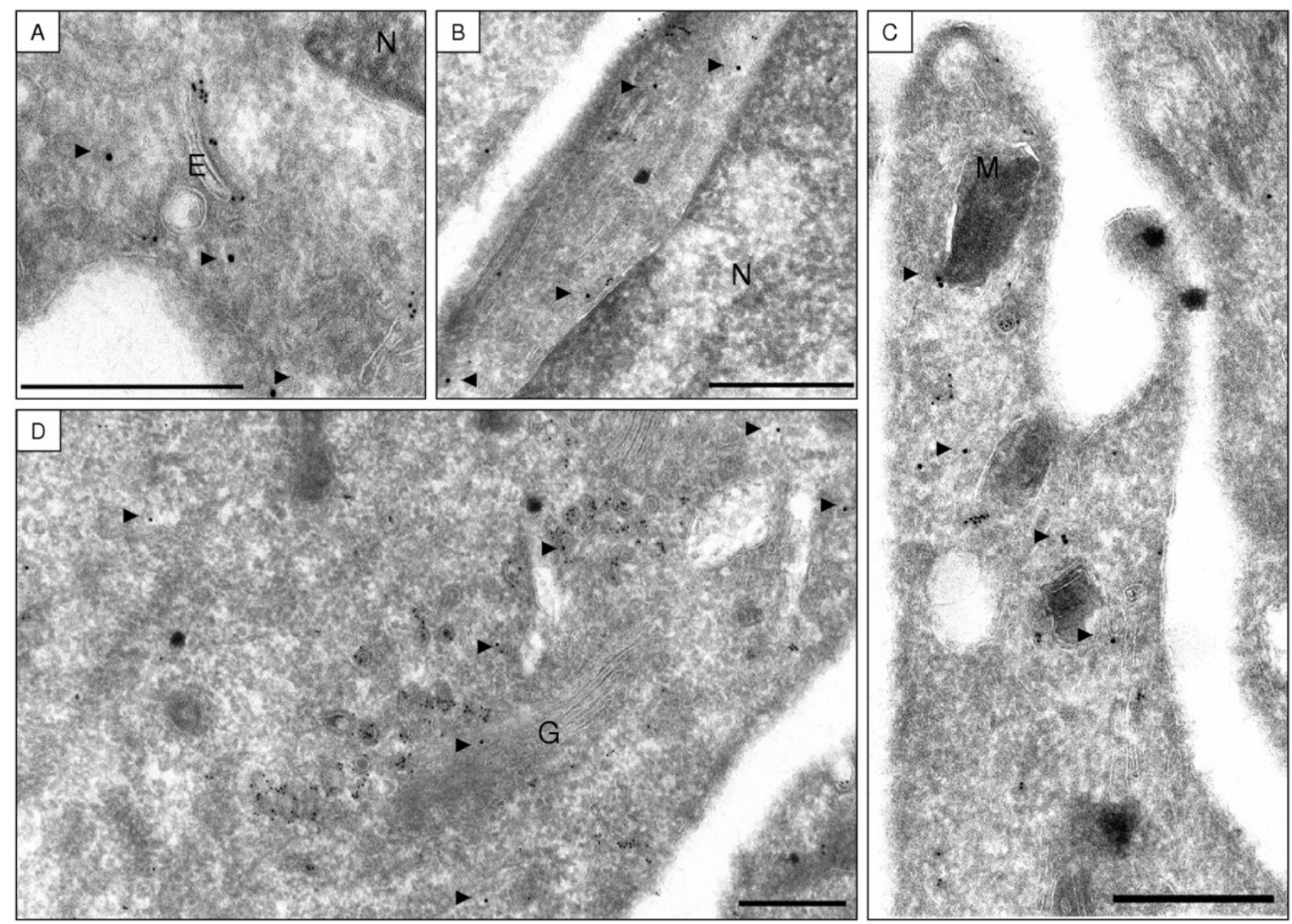

\section{Figure 4}

Immunoelectron micrographs demonstrating no co-localization of GFP-HPS3-delCBD and clathrin. Doublelabeling of anti-clathrin (10-nm gold) and anti-GFP (I5-nm gold) in normal melanocytes electroporated with GFP-HPS3-delCBD [A-D]. GFP-HPS3-delCBD (arrowheads) was largely cytoplasmic and distributed throughout the entire cell, from the perinuclear/Golgi region $[A, B, D]$ to the tips [C]. No co-localization of the two labels (GFP-HPS3-delCBD and clathrin) was observed. $\mathrm{N}=$ Nucleus, $\mathrm{G}=\mathrm{Golgi}, \mathrm{E}=$ Endosomal structure, $\mathrm{M}=$ Melanosome. Bar $=500 \mathrm{~nm}$

icles distributed throughout the cell [39]. This was in contrast to the situation in normal melanocytes, in which the small DOPA-positive vesicles were restricted to the Golgi region. A possible explanation is that HPS3 (and perhaps BLOC-2 as a whole) interacts with the small DOPA-positive vesicles via its clathrin-binding domain, escorting them from the Golgi region to premelanosomes for delivery of their contents. In such a scenario, additional specialized accessory factors (perhaps other HPS proteins or BLOCs) would regulate vesicle targeting, budding and fusion events, clathrin coat assembly and disassembly, and interactions with the cytoskeleton.

Future investigations should pursue the function of BLOC-2 with the recognition that one of its components,
HPS3, binds clathrin and may, therefore, bind to vesicles. This understanding allows for hypotheses regarding the roles of HPS5 and HPS6 in BLOC-2. Possible roles could include such functions as binding designated cargo, regulating conformational changes of the complex, or tethering proteins or vesicles for interactions with the BLOC-2 complex as a whole.

\section{Conclusion}

HPS3 associates with clathrin, predominantly on small clathrin-containing vesicles in the perinuclear region. This association most likely occurs directly via a functional clathrin-binding domain in HPS3 and is supported by immunoprecipitation, immunofluorescence, live cell imaging and immunoelectron microscopy data. 


\section{Methods}

\section{Patients and cells}

Normal human primary epidermal melanocytes used for immunoelectron microscopy were obtained from neonatal foreskin and established as described $[40,41]$. HPS-3 patient (HPS3 null) primary epidermal melanocytes and primary fibroblast cultures were obtained from skin biopsies and cultured as previously described [14]. All other normal human primary epidermal melanocytes were purchased from Cascade Biologics (Portland, OR). The HPS3 patients were enrolled in a protocol approved by the National Human Genome Research Institute Institutional Review Board to study the clinical and molecular aspects of HPS. Written informed consent was obtained from the patient or the patient's parent.

\section{Immunoprecipitation and western blotting}

Normal and HPS3 null melanocytes cell pellets were resuspended in PBS containing 1\% NP-40 and protease inhibitors (Roche Molecular Biochemicals, Indianapolis, IN). The cell lysates were cleared by centrifugation and the resulting supernatants were incubated with HPS3 polyclonal peptide antibody (developed in rabbit against the peptide KMGDLDMHRNEMKSHS) followed by incubation with protein A/G agarose beads (Oncogene Research Products, San Diego, CA). The agarose beads were washed, boiled in SDS-loading buffer and centrifuged. The resulting supernatants were electrophoresed on 4-12\% SDS-PAGE gels (Invitrogen, Carlsbad, CA) and electro-blotted onto nitrocellulose membranes (Schleicher and Schuell, Keene, NH). The membranes were blocked and incubated with mouse monoclonal anti-clathrin antibodies $(1: 1000)$ (BD Biosciences Pharmingen (San Diego, CA) or Affinity BioReagents (Golden, CO), followed by incubation with HRPconjugated anti-mouse IgG secondary antibodies (1:3000; Amersham Biosciences, Piscataway, NJ). Results were visualized with enhanced chemiluminescence (ECL Western Blotting Detection Reagents, Amersham Biosciences, Piscataway, NJ) and exposure to CL-XPosure film (Pierce Biotechnology, Rockford, IL) according to the manufacturer's instructions.

\section{GFP-HPS3 plasmid constructs}

The HPS3 coding sequence was amplified from normal human cDNA [GenBank: NM 032383] with sequence specific primers and subcloned into pEGFP-C1 (Clontech, Palo Alto, CA). Site-directed mutagenesis to replace the clathrin-binding motif (LLDFE) at residues 172-176 with the non-conserved amino acids AAAPG was performed with the QuikChange Site-Directed Mutagenesis Kit (Stratagene, La Jolla, CA) according to the manufacturer's recommendations, using the forward primer 5'-AATGAGGAATTCTCAGCAGCGGCCCCTGGACGTTCTTTAAT-
TATAC-3' and its reverse complement. All constructs were verified by sequencing before use.

\section{Transfections}

All transfections were performed by electroporation in an Amaxa nucleofector electroporator (Amaxa GmbH, Germany). Electroporation of melanocytes was performed as described [42]. Fibroblasts were electroporated using Amaxa reagents and $3 \mu \mathrm{g}$ of plasmid DNA with the U_23 nucleofector program.

\section{Fluorescence microscopy}

Approximately $16 \mathrm{~h}$ after transfection with either GFPHPS3 or GFP-HPS3-delCBD normal melanocytes were incubated at $20^{\circ} \mathrm{C}$ for $2 \mathrm{~h}$ to block trafficking out of the trans-Golgi $[35,36]$. Cells were transferred to $37^{\circ} \mathrm{C}$ for 5 min to release the temperature block and resume normal trafficking then fixed in 3\% paraformaldehyde. Melanocytes allowed to express GFP-HPS3 or GFP-HPS3-delCBD for longer than $24 \mathrm{~h}$ demonstrated some GFP aggregates and decreased viability. Slides were blocked in PBS containing $0.1 \%$ saponin, $100 \mu \mathrm{M}$ glycine, $0.1 \%$ BSA and $2 \%$ donkey serum followed by incubation with mouse monoclonal clathrin heavy chain antibodies (1:200 dilution; BD Biosciences Pharmingen). The cells were washed and incubated with donkey anti-mouse antibodies conjugated to ALEXA-555 (Molecular Probes), washed again, and mounted in VectaShield (Vector Laboratories, Burlingame, CA).

Live cell imaging was performed on HPS3 null fibroblasts expressing either GFP-HPS3 or GFP-HPS3-delCBD approximately $16 \mathrm{~h}$ after transfection. Cells were incubated at $20^{\circ} \mathrm{C}$ for $2 \mathrm{~h}$ followed by a 10 min incubation with the acidic vesicle dye Lysotracker Red (10 nM; Molecular Probes). The cells were then placed in fresh, prewarmed culture media and imaged on a $37^{\circ} \mathrm{C}$ warming stage. All cells were imaged with a Zeiss 510 META confocal laser-scanning microscope (Carl Zeiss, Microimaging Inc., Germany) using a 488 Argon and a 543 HeNe laser. Images were acquired using either a Plan Apochromat 63X/1.4 oil DIC or a 100× Plan Apochromat 100X/ 1.4 oil DIC objective.

\section{Immunoelectron microscopy}

Normal melanocytes were fixed approximately $9 \mathrm{~h}$ or 24 $\mathrm{h}$ after transfection in $2 \%$ paraformaldehyde with $0.2 \%$ glutaraldehyde in PHEM buffer for $2 \mathrm{~h}$. After embedding, cutting, cryoprotection and snap-freezing of the pellet, ultrathin cryosections were labeled with mouse monoclonal antibodies to clathrin (1:100) (BD Biosciences Pharmingen). The mouse monoclonal antibodies were indirectly labeled with 20 -nm protein A-gold particles via a rabbit anti-mouse IgG bridging antibody (1:200) (DakoCytomation, Denmark). The second labeling was 
performed with a rabbit polyclonal anti-GFP antibody (1:1000) [43], followed by 10 -nm protein A-gold incubation. To exclude co-labeling artifacts, ultrathin cryosections were labeled with primary antibodies as above, but incubated with 10-nm protein A-gold in the first labeling and 15-nm protein A-gold in the second labeling. The grids were contrasted with uranyl acetate and imaged with a Philips EM 410 electron microscope (Philips, Eindhoven, The Netherlands). Quantitation of anti-GFP immunogold labeling of cellular compartments and its association with clathrin (anti-clathrin immunogold labeling) was performed on randomly selected cells expressing either GFP-HPS3 (28 cells) or GFP-HPS3-delCBD (25 cells) [44].

\section{List of abbreviations}

HPS, Hermansky-Pudlak syndrome; BLOC, biogenesis of lysosome-related organelles complexes; GFP, green fluorescent protein; CBD, clathrin-binding domain; TGN, trans-Golgi network; DOPA, dihydroxyphenylalanine; PBS, phosphate buffered saline; BSA, bovine serum albumin; SDS-PAGE, sodium dodecyl sulfate-polyacrylamide gel electrophoresis; PHEM, PIPES, HEPES, EGTA, $\mathrm{MgCl}_{2}$

\section{Authors' contributions}

AHW performed the immunoprecipitations. AHW and $\mathrm{MH}$ prepared the plasmid constructs. AHW and HD carried out the cell culture, transfection experiments, immunofluorescence and live cell confocal imaging. WAG recruited the HPS-3 patient and established the fibroblast cultures. RB established the HPS-3 patient melanocyte cultures. Immunoelectron microscopy and quantitation was performed by WW and MM. WAG, MH, WW and AHW prepared the manuscript.

\section{Additional material}

\section{Additional file 1}

Time series of GFP-HPS3 and acidic vesicle live cell imaging. GFPHPS3 expressing HPS3 null fibroblast was imaged at $37^{\circ} \mathrm{C}$ following a 2 $h$ incubation at $20^{\circ} \mathrm{C}$. Time series (from inset in Figure $2 a[\mathrm{~A}]$ and Figure $2 b)$ showing a transient association of GFP-HPS3 with Lysotracker Red stained vesicles as they exit the perinuclear area.

Click here for file

[http://www.biomedcentral.com/content/supplementary/14712121-6-33-S1.mov]

\section{Acknowledgements}

We thank Prof. J. Fransen (Nijmegen, The Netherlands) for providing the polyclonal anti-GFP antibody, Prof. J. Klumperman (Utrecht, The Netherlands) for providing the monoclonal anti-clathrin antibodies, Prof. J. Lambert (Gent, Belgium) for providing normal human melanocytes, J. Onderwater and R. Limpens for assisting with electron microscopy and $\mathrm{L}$. Verschragen for preparation of electron micrographs. This research was supported in part by the Intramural Research Program of the National Human Genome Research Institute, National Institutes of Health.

\section{References}

I. Hermansky F, Pudlak P: Albinism associated with hemorrhagic diathesis and unusual pigment reticular cells in the bone marrow: report of two cases with histochemical studies. Blood 1959, I 4:162-169.

2. King RA, Hearing VJ, Creel DJ, Oetting WS: Albinism. In The Metabolic and Molecular Bases of Inherited Disease Volume 4. 8th edition. Edited by: Scriver CR, Beaudet AL, Valle DL, Sly WS. New York: McGraw-Hill; 200 I:5587-5627.

3. Huizing M, Anikster Y, Gahl WA: Hermansky-Pudlak syndrome and related disorders of organelle formation. Traffic 2000, I :823-835.

4. Huizing M, Boissy RE, Gahl WA: Hermansky-Pudlak syndrome: Vesicle formation from yeast to man. Pigment Cell Res 2002, I 5:405-419.

5. Simon JW, Adams RJ, Calhoun JH, Shapiro SS, Ingerman CM: Ophthalmic manifestations of the Hermansky-Pudlak syndrome (oculocutaneous albinism and hemorrhagic diathesis). Am J Ophthalmol 1982, 93:7|-77.

6. Summers CG, Knobloch WH, Witkop CJ, King RA: HermanskyPudlak syndrome. Ophthalmic findings. Ophthalmology 1988 , 95:545-554.

7. Iwata F, Reed GF, Caruso RC, Kuehl EM, Gahl WA, Kaiser-Kupfer MI: Correlation of visual acuity and ocular pigmentation with the I 6-bp duplication in the HPS-I gene of Hermansky-Pudlak syndrome, a form of albinism. Ophthalmology 2000, 1 07:783-789.

8. Witkop CJ, Krumwiede M, Sedano H, White JG: Reliability of absent platelet dense bodies as a diagnostic criterion for Hermansky-Pudlak syndrome. Am J Hematol I987, 26:305-3 I I.

9. Gahl WA, Brantly M, Kaiser-Kupfer MI, Iwata F, Hazelwood S, Shotelersuk V, Duffy LF, Kuehl EM, Troendle J, Bernardini I: Genetic defects and clinical characteristics of patients with a form of oculocutaneous albinism (Hermansky-Pudlak syndrome). $\mathrm{N}$ Engl J Med 1998, 338: I 258-I 264.

10. Brantly M, Avila NA, Shotelersuk V, Lucero C, Huizing M, Gahl WA: Pulmonary function and high-resolution $C T$ findings in patients with an inherited form of pulmonary fibrosis, Hermansky-Pudlak syndrome, due to mutations in HPS-I. Chest 2000, I I 7: I29-336.

II. Swank RT, Novak EK, McGarry MP, Rusiniak ME, Feng L: Mouse models of Hermansky-Pudlak syndrome: a review. Pigment Cell Res 1998, I I:60-80.

12. Simpson F, Peden AA, Christopoulou L, Robinson MS: Characterization of the adaptor-related protein complex, AP-3. J Cell Biol 1997, I 37:835-845.

13. Dell'Angelica EC, Shotelersuk V, Aguilar RC, Gahl WA, Bonifacino JS: Altered trafficking of lysosomal proteins in Hermansky-Pudlak syndrome due to mutations in the beta-3A subunit of the AP-3 adaptor. Mol Cell 1999, 3:II-2I.

14. Huizing M, Sarangarajan R, Strovel E, Zhao Y, Gahl WA, Boissy RE: AP-3 mediates tyrosinase but not TRP-I trafficking in human melanocytes. Mol Biol Cell 200I, I 2:2075-2085.

15. Clark RH, Stinchcombe JC, Day A, Blott E, Booth S, Bossi G, Hamblin T, Davies EG, Griffiths GM: Adaptor protein 3-dependent microtubule-mediated movement of lytic granules to the immunological synapse. Nature Immunol 2003, 4: I I I I- I I 20.

16. Oh J, Bailin T, Fukai K, Feng GH, Ho L, Mao JI, Frenk E, Tamura N, Spritz RA: Positional cloning of a gene for Hermansky-Pudlak syndrome, a disorder of cytoplasmic organelles. Nature Genet 1996, 14:300-306.

17. Dell'Angelica EC, Aguilar RC, Wolins N, Hazelwood S, Gahl WA, Bonifacino JS: Molecular characterization of the protein encoded by the Hermansky-Pudlak syndrome type I gene. J Biol Chem 2000, 275:1300-1306.

18. Anikster Y, Huizing M, White J, Shevchenko YO, Fitzpatrick DL, Touchman JW, Compton JG, Bale SJ, Swank RT, Gahl WA, Toro JR: Mutation of a new gene causes a unique form of HermanskyPudlak syndrome in a genetic isolate of central Puerto Rico. Nature Genet 200I, 28:376-380.

19. Huizing M, Anikster Y, Fitzpatrick DL, Jeong AB, D'Souza M, Rausche M, Toro JR, Kaiser-Kupfer MI, White JG, Gahl WA: Hermansky- 
Pudlak syndrome type 3 in Ashkenazi Jews and other nonPuerto Rican patients with hypopigmentation and platelet storage-pool deficiency. Am J Hum Genet 200I, 69:1022-1032.

20. Suzuki T, Li W, Zhang Q, Karim A, Novak EK, Sviderskaya EV, Hill SP, Bennett DC, Levin AV, Nieuwenhuis HK, Fong CT, Castellan C, Miterski B, Swank RT, Spritz RA: Hermansky-Pudlak syndrome is caused by mutations in HPS4, the human homolog of the mouse light-ear gene. Nature Genet 2002, 30:32I-324.

21. Anderson PD, Huizing M, Claassen DA, White J, Gahl WA: Hermansky-Pudlak syndrome type 4 (HPS-4): clinical and molecular characteristics. Hum Genet 2003, I I3:10-17.

22. Zhang Q, Zhao B, Li W, Oiso N, Novak EK, Rusiniak ME, Gautam R, Chintala S, O'Brien EP, Zhang Y, Roe BA, Elliott RW, Eicher EM, Liang $P$, Kratz C, et al.: Ru2 and Ru encode mouse orthologs of the genes mutated in human Hermansky-Pudlak syndrome types 5 and 6. Nature Genet 2003, 33:145-153.

23. Huizing M, Hess R, Dorward H, Claassen DA, Helip-Wooley A, Kleta R, Kaiser-Kupfer MI, White JG, Gahl WA: Cellular, molecular and clinical characterization of patients with Hermansky-Pudlak syndrome type 5 . Traffic 2004, 5:7| I-722.

24. Li W, Zhang Q, Oiso N, Novak EK, Gautam R, O'Brien EP, Tinsley CL, Blake DJ, Spritz RA, Copeland NG, Jenkins NA, Amato D, Roe BA, Starcevic M, Dell'Angelica EC, et al:: Hermansky-Pudlak syndrome type 7 (HPS-7) results from mutant dysbindin, a member of the biogenesis of lysosome-related organelles complex I (BLOC-I). Nature Genet 2003, 35:84-89.

25. Martina JA, Moriyama K, Bonifacino JS: BLOC-3, a protein complex containing the Hermansky-Pudlak syndrome gene products HPSI and HPS4. I Biol Chem 2003, 278:29376-29384.

26. Nazarian R, Falcon-Perez JM, Dell'Angelica EC: Biogenesis of lysosome-related organelles complex 3 (BLOC-3): A complex containing the Hermansky-Pudlak syndrome (HPS) proteins HPSI and HPS4. Proc Natl Acad Sci USA 2003, 100:8770-8775.

27. Novak EK, Sweet HO, Prochazka M, Parentis M, Soble R, Reddington $M$, Cairo A, Swank RT: Cocoa: a new mouse model for platelet storage pool deficiency. Br J Haematol 1988, 69:37| I-378.

28. Suzuki T, Li W, Zhang Q, Novak EK, Sviderskaya EV, Wilson A, Bennett DC, Roe BA, Swank RT, Spritz RA: The gene mutated in cocoa mice, carrying adefect of organelle biogenesis, is a homologue of the human Hermansky-Pudlak syndrome-3 gene. Genomics 200I, 78:30-37.

29. Dell'Angelica EC, Klumperman J, Stoorvogel W, Bonifacino JS: Association of the AP-3 adaptor complex with clathrin. Science 1998, 280:43|-434.

30. ter Haar E, Harrison SC, Kirchhausen T: Peptide-in-groove interactions link target proteins to the b-propeller of clathrin. Proc Natl Acad Sci USA 2000, 97: 1096-I I 00.

31. Kirchhausen T: Clathrin. Annu Rev Biochem 2000, 69:699-727.

32. Dell'Angelica EC: Clathrin-binding proteins: got a motif? Join the network! Trends Cell Biol 200I, I I:3I5-3I8.

33. Rappoport J, Simon S, Benmerah A: Understanding living clathrin-coated pits. Traffic 2004, 5:327-337.

34. Ehrlich M, Boll W, Van Oijen A, Hariharan R, Chandran K, Nibert M, Kirchhausen T: Endocytosis by random initiation and stabilization of clathrin-coated pits. Cell 2004, I I 8:59|-605.

35. Matlin KS, Simons K: Reduced temperature prevents transfer of a membrane glycoprotein to the cell surface but does not prevent terminal glycosylation. Cell 1983, 34:233-243.

36. Griffiths G, Pfeiffer S, Simons K, Matlin K: Exit of newly synthesized membrane proteins from the trans cisterna of the Golgi complex to the plasma membrane. J Cell Biol 1985 , 101:949-964.

37. Gautam R, Chintala S, Li W, Zhang Q, Tan J, Novak EK, Di Pietro SM, Dell'Angelica EC, Swank RT: The Hermansky-Pudlak syndrome 3 (cocoa) protein is a component of the biogenesis of lysosome-related organelles complex-2 (BLOC-2). J Biol Chem 2004, 279: I2935-12942.

38. Di Pietro SM, Falcon-Perez JM, Dell'Angelica EC: Characterization of BLOC-2, a complex containing the Hermansky-Pudlak syndrome proteins HPS3, HPS5 and HPS6. Traffic 2004, 5:276-283.

39. Boissy R, Richmond B, Huizing M, Helip-Wooley A, Zhao Y, Koshoffer A, Gahl W: Melanocyte-specific proteins are aberrantly trafficked in melanocytes of Hermansky-Pudlak syndrometype 3. Am J Pathol 2005, 165:23I-240.
40. Naeyaert JM, Eller M, Gordon PR, Park HV, Gilchrest BA: Pigment content of cultured human melanocytes does not correlate with tyrosinase message level. Br J Dermatol I99I, I 25:297-303.

4I. Smit NP, Kolb RM, Lenties EG, Noz KC, van der Meulen H, Koerten HK, Vermeer BJ, Pavel S: Variations in melanin formation by cultured melanocytes from different skin types. Arch Dermato Res 1998, 290:342-349.

42. Westbroek W, Lambert J, Bahadoran P, Roser B, Herteleer MC, Smit $\mathrm{N}$, Mommaas M, Ballotti R, Naeyaert JM: Interactions of human myosin $\mathrm{Va}$ isoforms, endogenously expressed in human melanocytes, are tightly regulated by the tail domain. J Invest Dermatol 2003, I 20:465-475.

43. Cuppen E, Wijers N, Schepens J, Fransen J, Wieringa B, Hendriks W: A FERM domain governs apical confinement of PTP-BL in epithelial cells. J Cell Sci 1999, I | 2:3299-3308.

44. Mayhew T: How to count your gold: A tutorial on TEM immunogold label quantification. Micro Anal 2005, 19:9-12. (EU)

Publish with BioMed Central and every scientist can read your work free of charge

"BioMed Central will be the most significant development for disseminating the results of biomedical research in our lifetime. "

Sir Paul Nurse, Cancer Research UK

Your research papers will be:

- available free of charge to the entire biomedical community

- peer reviewed and published immediately upon acceptance

- cited in PubMed and archived on PubMed Central

- yours - you keep the copyright
BiolMedcentral 